\title{
PENGEMBANGAN SISTEM PENGAMAN PINTU LABORATORIUM ROBOTIKA UIN SULTAN SYARIF KASIM BERDASARKAN SIULAN BERBASIS SENSOR FC-04 DAN MIKROKONTROLER ATMEGA 328
}

\author{
Oktaf Brillian Kharisma ${ }^{1}$, Hanif Burhanuddin Putra Utama ${ }^{2}$ \\ 1,2 \\ Teknik Elektro, Fakultas Sains dan Teknologi, UIN Sultan Syarif Kasim \\ Pekanbaru, Riau \\ e-mail: brilliankhar@gmail.com, hanif.burhanuddin.p.u@students.uin-suska.ac.id
}

\begin{abstract}
Abstrak
Perkembangan teknologi berdampak positif bagi kehidupan manusia. Sistem rumah pintar yang sedang berkembang pesat dituntut agar dapat melayani konsumen. Sehingga, konsumen dapat merasakan keuntungan dari teknologi tersebut. Mengingat angka pencurian di Indonesia yang semakin meningkat dan perlunya sistem keamanan yang mampu bekerja terus menerus secara otomatis. Maka dari itu, dalam penelitian ini dikembangkan sebuah sistem pengaman kunci pintu otomatis sesuai dengan kondisi laboratorium robotika UIN Sultan Syarif Kasim. Berdasarkan pengujian yang telah dilakukan pada alat tersebut, maka dapat disimpulkan bahwa alat ini telah diuji dan dapat digunakan untuk membantu sistem keamanan pada pintu rumah berdasarkan intensitas suara dari siulan yang diterima oleh sensor suara FC -04 sebesar 91,1 dBA sampai 95,4 dBA.
\end{abstract}

Kata kunci: Arduino Uno, Selenoid, Relay, Sensor Suara FC -04

\begin{abstract}
The developments of technology have a positive impact on human life. The fast growing smart home system is demanded to serve consumers. Thus, consumers can feel the benefits of the technology. Given the increasing number of thefts in Indonesia and the need for a security system that is able to work continuously automatically. Therefore, in this study developed an automatic door lock security system in accordance with the laboratory conditions of UIN Sultan Syarif Kasim robotics. Based on the tests that have been performed on the tool, it can be concluded that this tool has been tested and can be used to help the security system on the door of the house based on the sound intensity of whistles received by the FC -04 voice sensor of $91.1 \mathrm{dBA}$ to $95.4 \mathrm{dBA}$
\end{abstract}

Keywords: Arduino Uno, Solenoid, Relay, FC-04 Sensor

\section{PENDAHULUAN}

Pada saat ini sistem keamanan pada laboratorium robotika UIN sultan syarif kasim masih menggunakan sistem keamanan manual dan kurang praktis dalam pengelolaannya. Sehingga, sangat merepotkan dalam segi pengelolaan ataupun maintenance-nya. Sebab, setiap civitas yang akan mengakses harus menggandakan kunci terlebih dahulu dan tak jarang dapat menimbulkan kerusakan pada rumah kuncinya. Disamping letaknya yang sebagian besar masih di kelilingi oleh hutan dan jauh dari keramaian, menyebabkan terjadinya bahaya pencurian.

Di sisi lain, berdasarkan data yang terhimpun oleh Badan Pusat dan Statistik 2016. Bahwa angka kejahatan pencurian diindonesia setiap tahunnya meningkat, hal ini dapat dilihat dari data berikut : pencurian pada tahun $2011 \quad$ (10.097 kejahatan), tahun 2012 (10.672 kejahatan), tahun 2013 (10.683 kejahatan)(Badan Pusat Statistik, 2016). Karena, terdapat permasalahan yang sering muncul tersebut. 
Maka, dibutuhkan suatu sistem perangkat keamanan yang dapat menjaga keamanan setiap waktu. Dengan berkembangnya teknologi pada saat ini, dapat mengurangi angka kriminalitas yang terjadi di masyarakat khususnya tindak kejahatan pencurian.

Teknologi mikrokontroler yang saat ini tengah berkembang dapat dimanfaatkan untuk membuat sistem pengaman rumah dengan sensor suara FC-04 menggunakan selenoid door lock melalui volume suara pemilik rumah yang akan dideteksi terlebih dahulu kemudian diatur kapasitas dari intensitas suara tersebut. Jika tidak memenuhi intensitas suara dari sensor maka selenoid tidak akan terbuka.

Mikrokontroler Arduino adalah sebuah platform dari physical computing yang bersifat open source (Shabani, Julai, Ahmed, Helmi, \& Rose, n.d.) (Ario, 2015). Yang dimaksud platform dari physical computing adalah sebuah sistem atau perangkat fisik yang menggunakan software dan hardware yang sifatnya interaktif yaitu dapat menerima rangsangan dari lingkungan dan merespon balik. Physical computing merupakan sebuah konsep untuk memahami hubungan yang manusiawi antara lingkungan yang sifat alaminya gabungan dari system analog dengan dunia digital(Stankovic, Lee, Mok, \& Rajkumar, 2005). Dengan konsep inilah maka sistem dapat diaplikasikan dalam desain - desain alat atau projek-projek yang menggunakan sensor dan mikrokontroler. Dan yang dimaksud dengan sifat Arduino yang open source dimana tidak hanya softwarenya saja yang open source melainkan hardwarenya pun open source dimana diagram rangkaian elektronik arduino yang digratiskan kepada semua orang(Raka Agung, 2012).

Sensor suara FC-04 adalah teknologi yang mampu mengidentifikasi suara dengan keluarannya berupa bilangan binner (1 0 ) atau bernilai high dan low. Intensitas suara dapat dimodifikasi pada potensiometer sesuai keinginan kita kemudian data atau sinyal dari sensor akan diolah pada Arduino Uno dan selanjutnya relay yang menjadi switch untuk selenoid akan melakukan perintah yang dikirim dari
Arduino Uno((Saputro, Eko dan Wibawanto, 2016).

Selenoid sendiri merupakan actuator yang mampu melakukan gerakan linear yaoti gerakan lurus menarik dan mendorong. Solecoid DC bekerja secara elektromagnetis dengan memberikan sumber tegangan (Saputro, Eko dan Wibawanto, 2016). Ada beberapa jenis pintu sesuai fungsinya, seperti : pintu ayun, pintu geser, pintu lipat, dan pintu putar. Solenoid sebagai pengunci pintu dapat diletakkan pada posisi yang berbeda dan berbagai jenis pintu. Ada dua mekanisme utama yang bisa digunakan, untuk tujuan penguncian: Biasanya-Tertutup (NC) atau Normally-Open (NO) (Lawu et al., 2016) dan (S. Anderson, 2014).

Pada penelitian ini akan meneliti sensitifitas sensor FC-04 untuk sistem pengamanan pintu laboratorium robotika di UIN Sultan Syarif Kasim yang dapat memudahkan pengguna dalam melakukan kegiatan sehari-hari dan meningkatkan sistem keamanan pada rumah. Sebenarnya sudah ada penelitian mengenai sistem ini sebelumnya tetapi pada penelitian tersebut fiturnya masih bisa dilakukan pengembangan lebih lanjut mengenai sensitifitas dari sensor F-04 yang akan di gunakan dalam penelitian ini.

\section{METODE}

Alur penelitian ini secara garis besar dapat dilihat pada Gambar 1. Metode yang digunakan dalam penelitian adalah seperti berikut.

1. Pengamatan/Observasi dilakukan dengan menyebarkan angket kepada mahasiswa dan civitas disekitaran kampus mengenai perlu atau tidaknya alat kunci otomatis ini dibuat.

2. Studi Literatur dilakukan dengan mencari dan mempelajari artikel dan buku yang digunakan sebagai bahan acuan untuk mengkaji dasar teori.

3. Perancangan Hardware dilakukan dengan membuat rancangan sistem pengaman pintu otomatis. Pada 
tahap ini yang dilakukan adalah

merancang sistem elektronika.



Gambar 1. Alur Kerja Penelitian

4. Perancangan Software dilakukan dengan membuat simulasi terlebih dahulu di proteus sebelum nantinya di implementasikan ke hardware yang telah dibuat dengan menggunakan rule yang telah di tentukan terlebih dahulu berdasarkan kondisi dari lingkungan laboratorium.

5. Analisa Hasil dilakukan dengan mengamati untuk mengetahui dan memahami cara kerja perangkatkeras dan perangkat-lunak yang telah dibuat. Kemudian, di analisis dan disimpulkan.
Pada perancangan pengaman pintu otomatis di bagi kedalam dua bagian yaitu perancangan perangkat-keras (elektronik dari sistem) dan perangkat-lunak.

Tahap pertama yaitu membuat perancangan perangkat keras elektronik dan prototipe dari pengaman pintu otomatis Perangkat keras pada sistem ini dibagi dalam beberapa bagian, yakni sensor F-04 arduino uno dengan mikrokontroler AVR ATMEGA328, penampil LCD 2x16, solenoid, dan baterai sebagai catu daya untuk keseluruhan sistem. Secara umum blog system dapat dilihat pada Gambar 2.

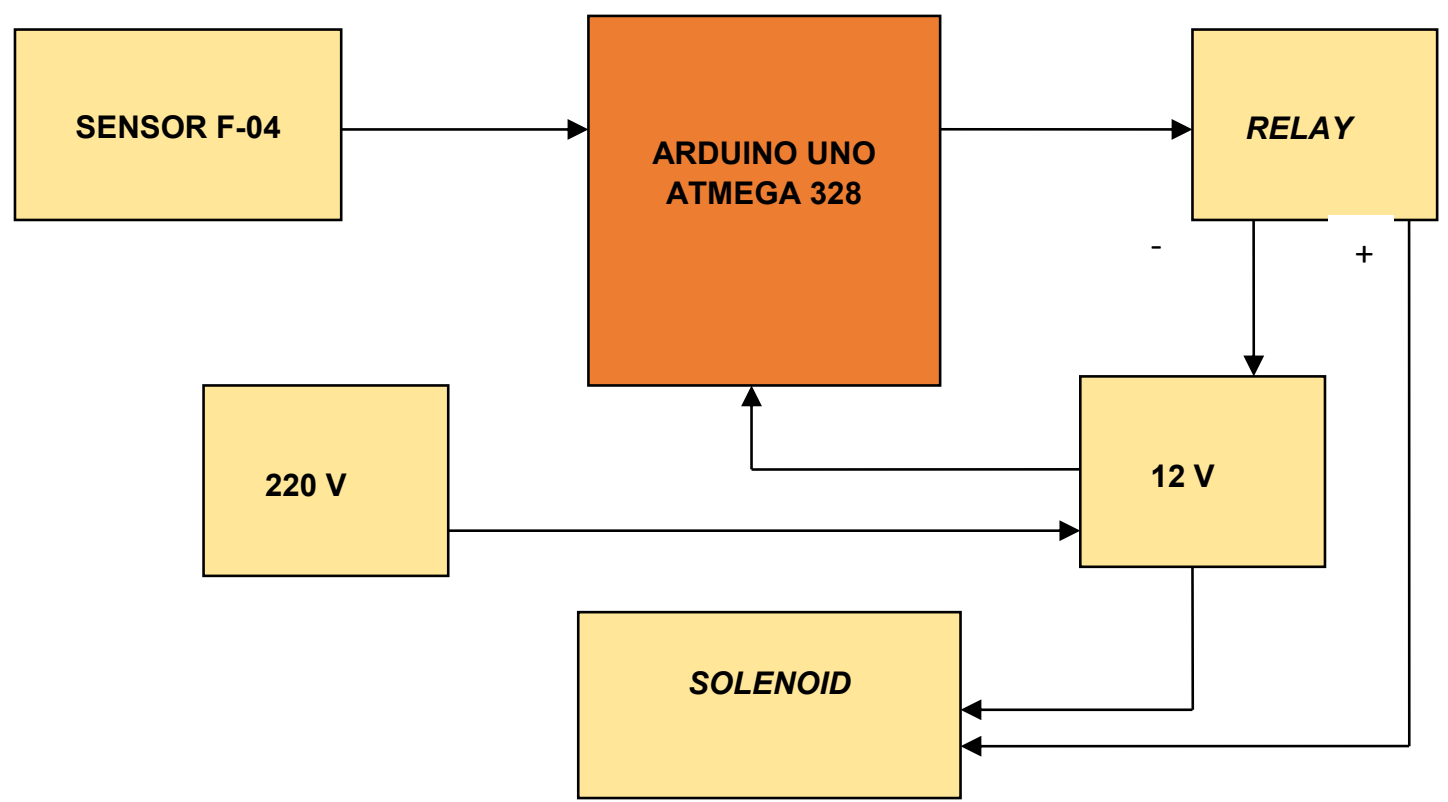

Jurnal Sains dan Teknologi | 116 
Gambar 2. Diagram Sistem Perangkat Keras Pengaman Pintu Otomatis.

Pengaman pintu otomatis ini menggunakan sensor F-04 sebagai masukkan untuk mengendalikan solenoid yang terpasang pada pintu. Sensor F-04 merupakan sensor suara yang memiliki harga murah dan terjangkau. Suara siulan pengguna akan diterima oleh sensor F-04. Kemudian akan diteruskan ke Arduino uno yang berbasis ATmega 382 . Pada perangkat mikrokontroller tersebut dirancang sebuah program yang berjalan seperti yang di tunjukkan pada Gambar 3. Tidak semua suara yang diterima oleh sensor F-04 yang dapat digunakan untuk mengendalikan selonoid yang dipasang pada pintu. Setiap suara siulan akan di filter bedasarkan besaran decibel $(\mathrm{dB})$ yang dibuat pada program mikrokontroler, yaitu ditentukan sekitar 90 dBA sampai 97 dBA. Ketika suara siulan sesuai dengan besaran decibel. Maka, Solenoid akan bergerak dan pintu akan terbuka. Kemudian, setiap informasi kondisi dari sistem akan di tampilkan pada LCD $2 \times 16$. Desibel yang terukur dengan menggunakan aplikasi Sound Analyzer.

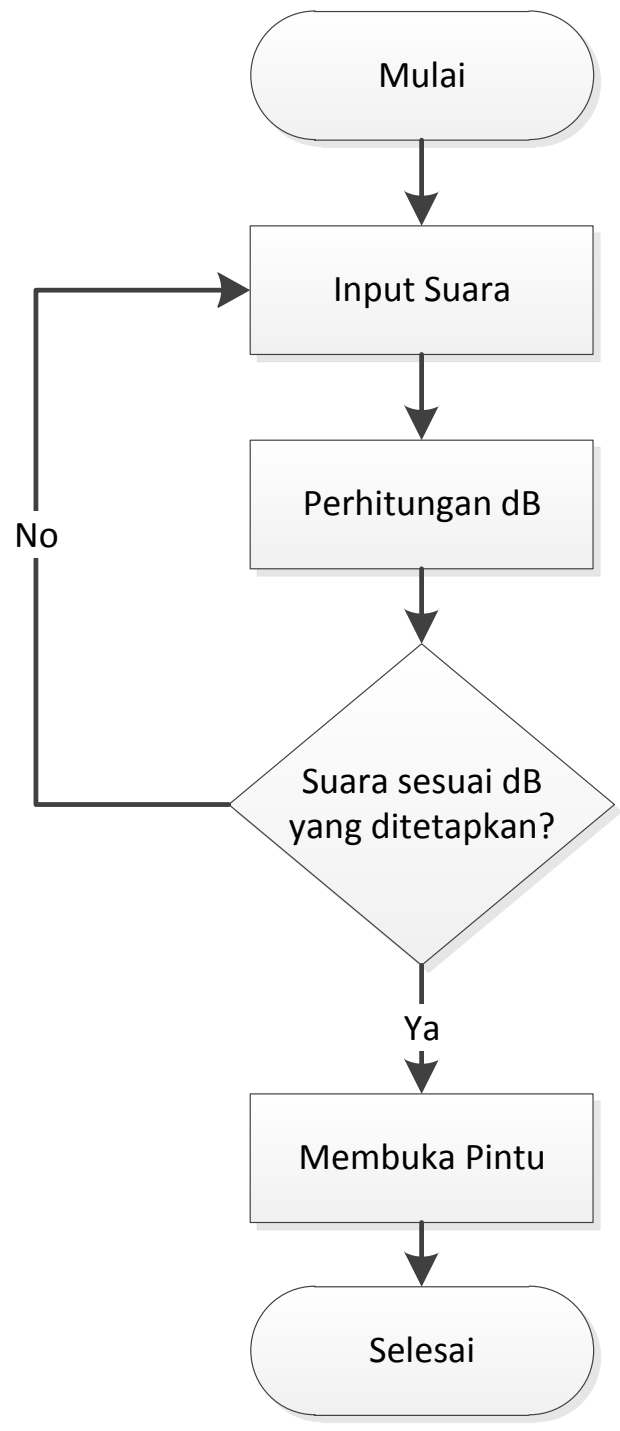

Gambar 3. Alur program pada mikrokontroller 


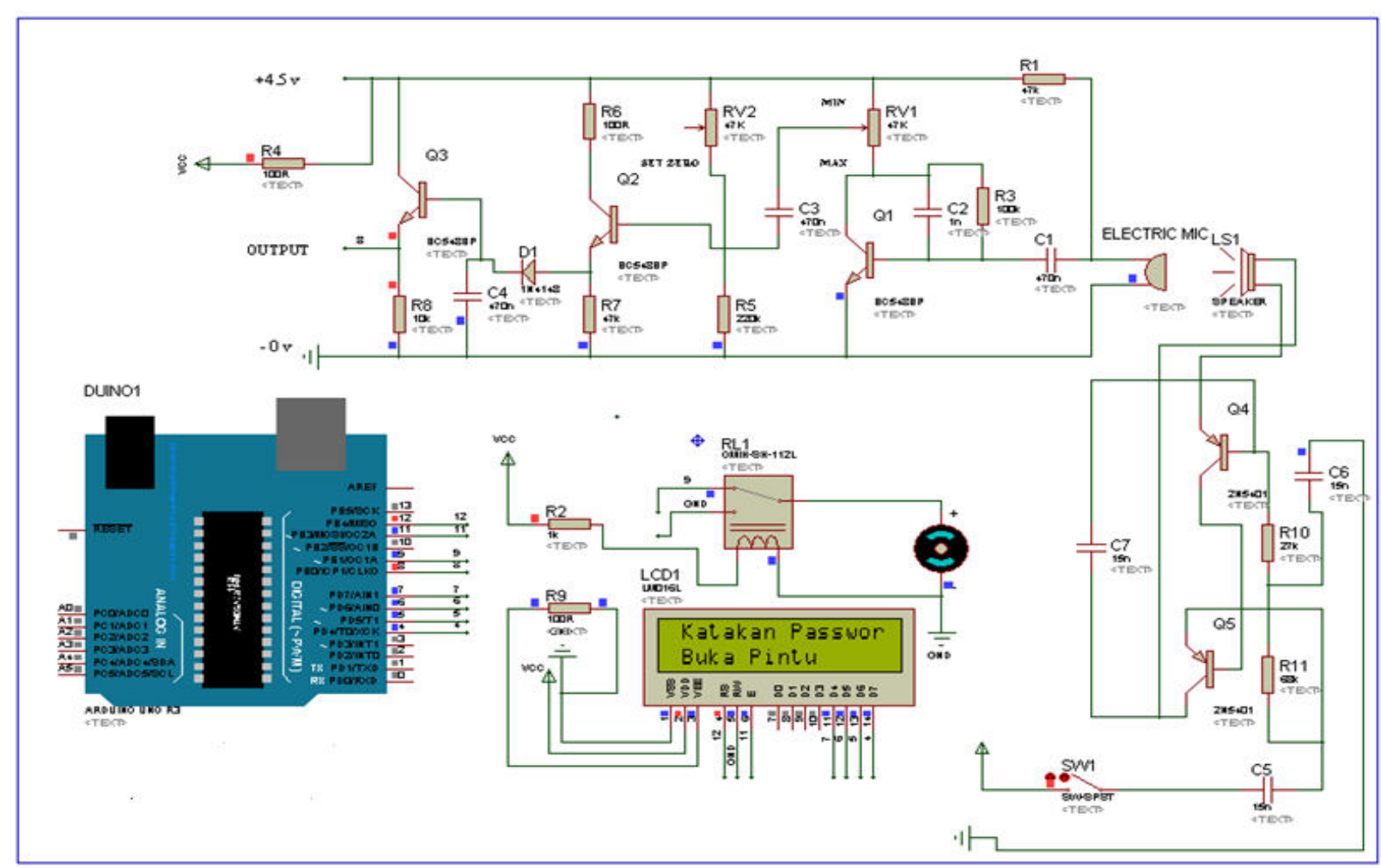

Gambar 4. Skematik Pengaman Pintu Otomatis

\section{.Perancangan Wiring pada Sensor}

Secara umum perancangan skematik pengaman pintu dapat dilihat pada Gambar 4. Adapun langkah-langkah dalam implementasinya dapat dilakukan beberapa tahap, yang pertama yaitu, tahap perancangan wiring sensor yang dilakukan adalah menghubungkan pin sensor ke pin Arduino Uno dengan kabel jumper terlihat pada Gambar 4, dan berikut penjelasan mengenai pin yang saling terhubung:

1. Pin VCC sensor terhubung dengan pin 5 $\checkmark$ Arduino.

2. Pin GND sensor terhubung dengan pin GND Arduino.

3. Pin Output sensor terhubung dengan pin 8 (digital) Arduino.

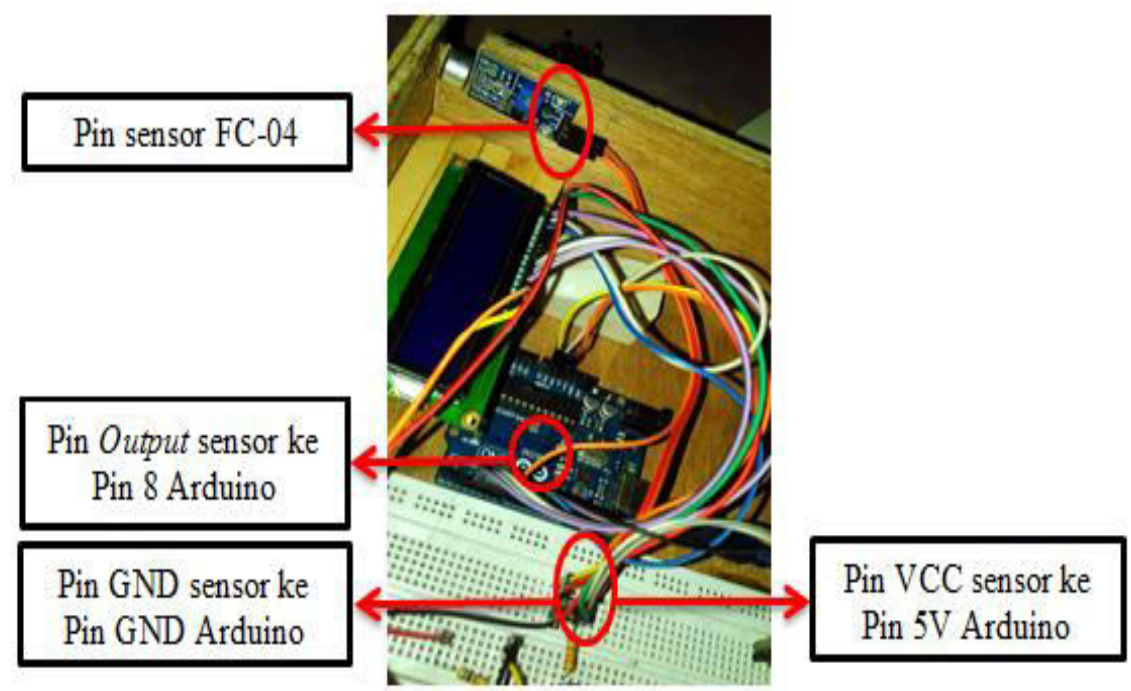

Gambar 5 Perancangan Wiring pada Sensor Suara dengan Arduino Uno. 


\section{Perancangan Wiring pada LCD}

Perancangan wiring pada LCD terlihat pada Gambar 6, yang dilakukan adalah menghubungkan pin-pin LCD dengan pin arduino menggunakan kabel jumper berikut penjelasan mengenai pin yang saling terhubung :

1. Pin VSS LCD terhubung dengan pin GND arduino.

2. Pin VDD LCD terhubung dengan pin $5 \mathrm{~V}$ arduino.

3. Pin VO LCD terhubung dengan pin GND arduino yang terlebih dahulu diberi hambatan sebesar $560 \mathrm{Ohm}$.

4. Pin RS LCD terhubung dengan pin 12 arduino. Dimana pin RS(Register Select) memiliki 2 fungsi dalam 2 keadaan yaitu:

a. Ketika HIGH = Untuk mengirim data[5].

b. Ketika LOW = Untuk mengirim instruksi[5].

5. Pin RW LCD terhubung dengan pin GND arduino. Dimana pin RW (Read/Write) hanya bernilai $H I G H$ untuk membaca data di LCD[5].
6. Pin E LCD terhubung dengan pin 11 arduino. Dimana pin $E(E n a b l e)$ harus bernilai HIGH supaya LCD dapat diakses[5].

7. Pin D4 LCD terhubung dengan pin 7 arduino. Dimana pin D4 LCD sebagai data bus.

8. Pin D5 LCD terhubung dengan pin 6 arduino. Dimana pin D5 LCD sebagai data bus.

9. Pin D6 LCD terhubung dengan pin 5 arduino. Dimana pin D6 LCD sebagai data bus.

10. Pin D7 LCD terhubung dengan pin 4 arduino. Dimana pin D7 LCD sebagai data bus[5].

11. Pin A LCD terhubung dengan pin $5 \mathrm{~V}$ arduino yang sebelumnya diberi hambatan sebesar 220 ' $\mathrm{S}$. Dimana pin A LCD ini sebagai catu daya positif untuk layar.

12. Pin K LCD terhubung dengan pin GND arduino. Dimana pin K LCD ini sebagai catu daya negatif untuk layar.

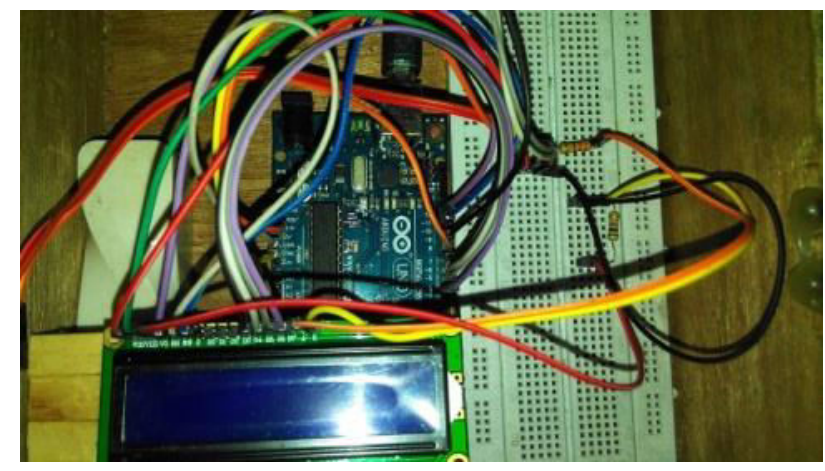

Gambar 6. Perancangan Wiring pada LCD dengan Arduino Uno.

\section{Perancangan Wiring pada Relay.}

Bahwa pada tahap yang terlihat pada Gambar 7. yang dilakukan adalah menghubungkan pin-pin pada relay dengan power supply, selenoid dan arduino. Berikut penjelasan dari pin-pin yang terhubung:

1. Pada pin input yaitu pin VCC relay terhubung dengan pin $5 \mathrm{~V}$ arduino, pin GND relay terhubung dengan pin GND
Arduino dan pin IN relay terhubung dengan pin 9 arduino.

2. Pada pin output yaitu pin NC(Normally Close) relay terhubung dengan GND dari selenoid, pin $\operatorname{COM(Change~Over)~relay~}$ terhubung dengan ground power supply dan pin $\mathrm{NO}$ (Normally Open) relay tidak digunakan karena sensor suara menggunakan logika LOW. 


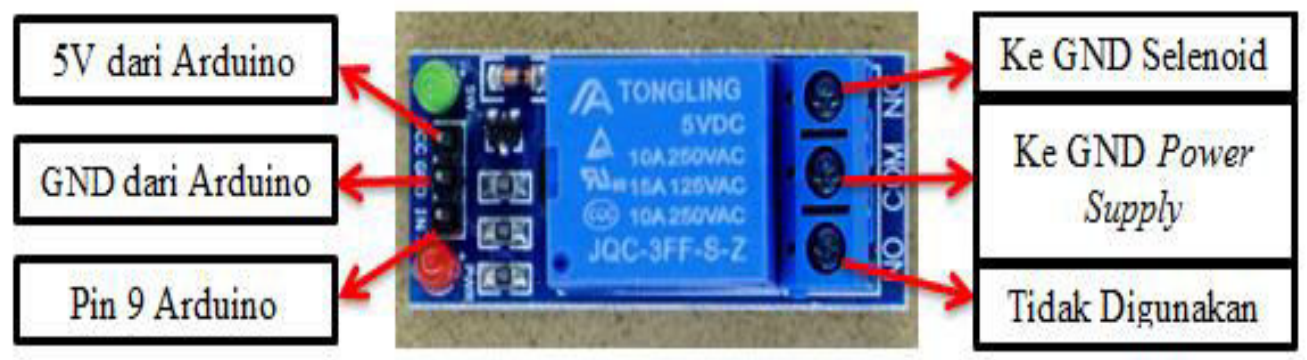

Gambar 7. Rangkaian Wiring pada Relay.

\section{Perancangan Wiring pada Selenoid.}

Pada tahap ini yang dilakukan yaitu dengan menghubungkan pin selenoid dengan power supply dan relay. Berikut penjelasan Gambar 8. mengenai pin yang terhubung :

1. Pada pin positif selenoid terhubung dengan 12V dari power supply.

2. Pada pin negatif selenoid terhubung dengan pin NC(Normally Close) relay.



Gambar 8 Rangkaian Wiring pada Selenoid.

\section{Perancangan Wiring pada Power Supply.}

Pada tahap ini penghubungan kabel tidaklah sulit karena sudah menjadi modul power supply yang siap pasang. Penjelasan Gambar 9 mengenai pemasangan pin-pin pada power supply adalah sebagai berikut:

1. Pada pin input power supply yaitu 15 , CT, 15 dihubungkan dengan pin output travo dengan nilai yang sama yaitu 15 , CT, 15 juga.
2. Pada pin output power supply yaitu keluaran yang positif dihubungkan dengan pin positif selenoid dan keluaran negatif dihubungkan dengan pin $\operatorname{COM}($ Change Over) dari relay.

3. Pada pin C, B, E power supply terhubung dengan pendingin untuk power supply itu sendiri.

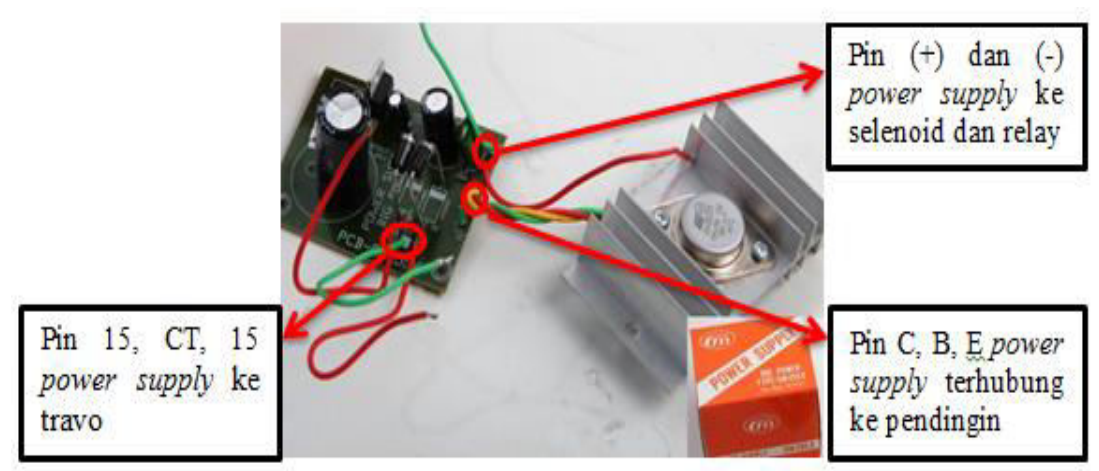

Gambar 9. Rangkaian Wiring pada Power Supply 


\section{Perancangan Wiring pada Travo.}

Pada tahap ini yang dilakukan adalah menghubungkan pin output travo ke power supply. Penjelasan Gambar 10. dari pin-pin yang terhubung yaitu:

Pada input dari travo langsung dari arus litrik AC sebesar $220 \mathrm{~V}$ yang ada dirumah-rumah pada umumnya sehingga tidak sulit untuk menggunakannya.

Pada output travo, pin tegangan yang digunakan yaitu pada pin $15 \mathrm{~V}$, CT dan $15 \mathrm{~V}$ agar jika memasuki power supply tegangan dapat dikurangi.

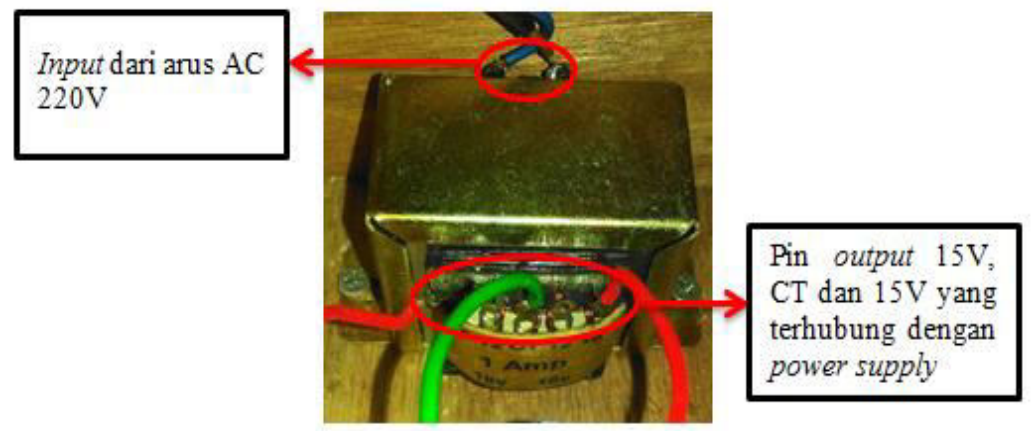

Gambar 10. Rangkaian Wiring pada Travo

Perancangan Wiring pada Arduino Uno.

Pada tahap ini semua komponen pendukung di hubungkan dengan Arduino, lihat Gambar 11. Berikut penjelasan pin-pin arduino yang terhubung dengan komponen pendukung tersebut:

1. Pin $5 \mathrm{~V}$ arduino terhubung dengan pin input sensor suara FC-04, terhubung dengan pin VDD dan pin A pada LCD serta terubung dengan pin input relay.

2. Pin GND arduino terhubung dengan pin GND sensor suara FC-04, terhubung dengan pin GND dari relay, serta terhubung degnan pin VSS, pin RW dan pin K pada LCD.
3. Pin 4 arduino terhubung dengan pin D7 pada LCD.

4. Pin 5 arduino terhubung dengan pin D6 pada LCD.

5. Pin 6 arduino terhubung dengan pin D5 pada LCD.

6. Pin 7 arduino terhubung dengan pin D4 pada LCD.

7. Pin 8 arduino terhubung dengan pin input sensor suara FC-04.

8. Pin 9 arduino terhubung dengan pin input relay.

9. Pin 11 arduino terhubung dengan pin $\mathrm{E}$ pada LCD.

10. Pin 12 arduino terhubung dengan pin RS pada LCD.

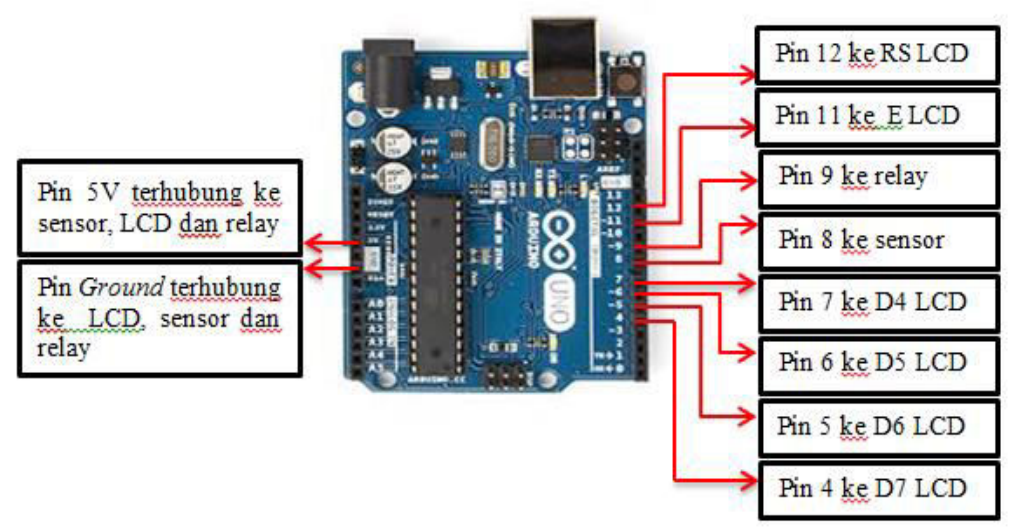

Gambar 11. Rangkaian Wiring pada Arduino Uno. 


\section{HASIL DAN PEMBAHASAN}

\author{
Setelah dilakukan perangkaian pada \\ setiap komponen. Kemudian, akan \\ dilakukan pengujian akhir dari system. \\ Pada pengujian ini dilakukan beberapa \\ tahap antara lain:
}

\section{Pengujian Berdasarkan Jarak Sumber Suara}

1. Keadaan Tidak Menerima Suara

Sensor suara FC-04 menerima berbagai jenis suara namun suara tersebut harus memenuhi intensitas suara yang telah diatur pada potensiometernya. Sensor ini haya bernilai high jika menerima suara yang memenuhi intensitasnya dan jika kurang maka sensor ini akan tetap low. Sensor FC-04 berlogika 1 dan 0 saja dan kepekaan dari sensor ini diatur pada potensimeternya. Dalam keadaan tidak menerima suara kunci pintu(selenoid) tudak akan terbuka dan dalam keadaan low atau berlogika 0 . Proses kerja sistem ketika menerima suara yaitu ketika sensor mendeteksi suara kemudian mengirim ke arduino dalam bentuk sinyal analog. Setelah sinyal input diterima selanjutnya akan diproses pada pengendali kemudian setelah input terbaca oleh pengendali maka diteruskan pada relay. Relay berperan sebagai switch untuk selenoid ketika high atau berlogika 0 maka kunci(selenoid) tidak akan terbuka. Keadaan tersebut dapat dilihat pada gambar 12 .

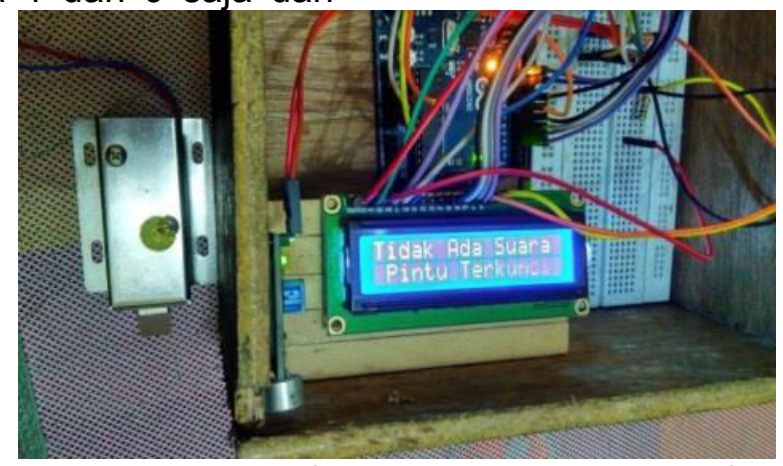

Gambar 12. Ketika Sensor Tidak Menerima Suara

2. Keadaan Menerima Suara

Pada keadaan ini sensor menerima suara yang memenuhi intensitasnya dan bernilai high atau berlogika 1. Sehingga sensor dapat mengirim sinyal input kepada arduino. Kemudian diproses dan keluarlah perintah untuk relay dari arduino, dan relay dalam keadaan normally close sehingga selenoid akan terbuka. Untuk pemilik rumah harus paham dengan jumlah intensitas dari sensor suara sehingga tidak sulit untuk mengucapkan perintah. Berikut gambar keadaan ketika sensor menerima suara:

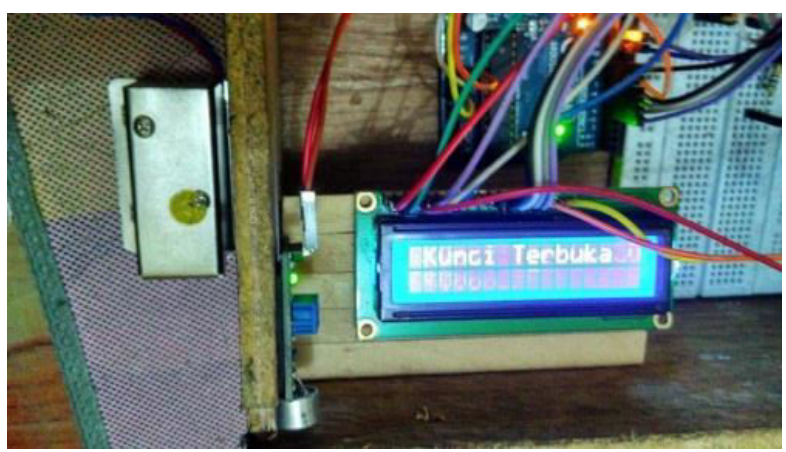

Gambar 13. Ketika Sensor Menerima Suara 
Tabel 1. Hasil Percobaan Kunci Pintu Otomatis Secara Umum

\begin{tabular}{cccccc}
\hline \multirow{2}{*}{ Percobaan } & \multirow{2}{*}{ Jarak $(\mathrm{cm})$} & \multicolumn{2}{c}{ Keadaan Kunci (Selenoid) } & \multicolumn{2}{c}{ Nilai Sensor } \\
& Terbuka & Terkunci & High (1) & Low (0) \\
\hline 1 & 50 & $\sqrt{ }$ & - & $\sqrt{ }$ & - \\
2 & 100 & $\sqrt{ }$ & - & $\sqrt{ }$ & - \\
3 & 150 & $\sqrt{ }$ & - & $\sqrt{ }$ & - \\
4 & 200 & - & $\sqrt{ }$ & - & $\sqrt{ }$ \\
5 & 250 & - & $\sqrt{ }$ & - & $\sqrt{ }$ \\
\hline
\end{tabular}

Dari Tabel 1 diatas dapat disimpulkan bahwa jarak sangat mempengaruhi nilai intensitas dari sensor. Berikut penjelasan setiap percobaan yang dilakukan:

1. Percobaan 1

Pada percobaan ini, dilakukan dengan jarak $50 \mathrm{~cm}$ atau $1 / 2 \mathrm{~m}$. Sensor dapat mendeteksi suara sehingga relay pada keadaan normally close dan selenoid terbuka.

2. Percobaan 2

Pada percobaan ini, dilakukan dengan jarak $100 \mathrm{~cm}$ atau $1 \mathrm{~m}$. Sensor dapat mendeteksi suara karena telah memenuhi intensitasnya.

3. Percobaan 3

Pada percobaan ini, dilakukan dengan jarak $150 \mathrm{~cm}$ atau $1,5 \mathrm{~m}$. Sensor masih dapat mendeteksi suara dan selenoid terbuka.

4. Percobaan 4

Pada percobaan ini dilakukan dengan jarak $200 \mathrm{~cm}$ atau $2 \mathrm{~m}$. Sensor tidak dapat mendeteksi suara karena jarak yang lumayan jauh dan intensitas suara dari sensor tidak terpenuhi sehingga selenoid terkunci.

5. Percobaan 5

Pada percobaan ini dilakukan dengan jarak $250 \mathrm{~cm}$ atau $2,5 \mathrm{~m}$. Percobaan kali ini sama halnya dengan percobaan 4 , dimana sensor tidak dapat mendeteksi suara sehingga menyebabkan relay tetap dalam keadaan normally open (terbuka) sehingga selenoid terkunci (berlogika 0).

\section{Pengukuran Intensitas Suara}

Pengukuran ini dilakukan dengan menggunakan aplikasi sound analyzer. Aplikasi ini merupakan aplikasi yang digunakan untuk mengukur batas minimum dan maksimum dari suara. Oleh karena itu penggunaannya sangat cocok dengan alat yang dibuat. Dari alat ini dapat mengetahui suara yang diterima oleh sensor, sehingga sensor tersebut bekerja sebagai input bagi Arduino Uno. Hasil penggukuran decibel suara yang dapat di olah oleh sistem menggunakan aplikasi sound analyzer dapat dilihat pada Tabel 2 dan Gambar 14.

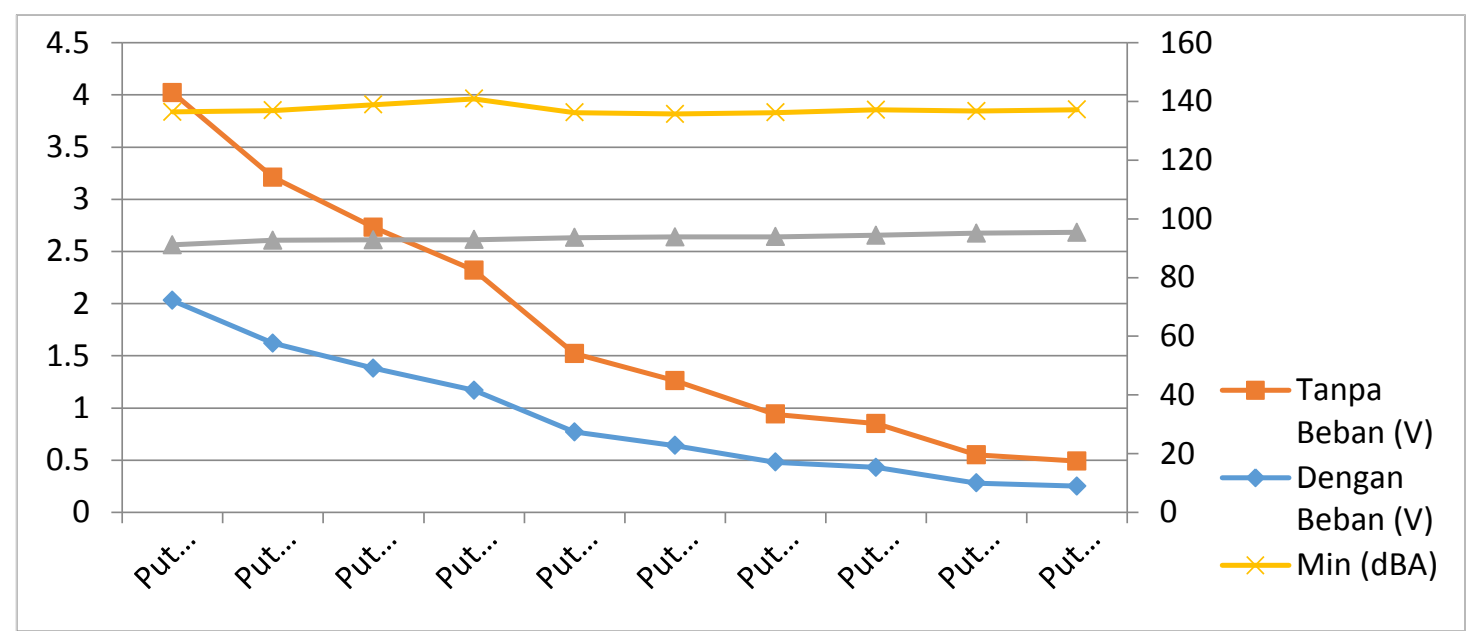

Gambar 14. Grafik Pengukuran Tegangan Potensiometer Sensor dan Nilai Intensitas Sensor. 
Tabel 2. Pengukuran Intensitas Suara.

\begin{tabular}{|c|c|c|c|c|c|}
\hline \multirow{2}{*}{$\begin{array}{l}\text { Jumlah } \\
\text { Putaran } \\
\text { Potensio }\end{array}$} & \multicolumn{2}{|c|}{$\begin{array}{l}\text { Nilai Pengukuran } \\
\text { Potensio (V) }\end{array}$} & \multicolumn{2}{|c|}{$\begin{array}{c}\text { Nilai Pengukuran } \\
\text { dengan sound } \\
\text { analyzer }\end{array}$} & \multirow[t]{2}{*}{ Keterangan } \\
\hline & $\begin{array}{c}\text { Dengan } \\
\text { beban }\end{array}$ & $\begin{array}{l}\text { Tanpa } \\
\text { Beban }\end{array}$ & Min. & Max. & \\
\hline $\mathrm{Ke}-1$ & $2.03 \mathrm{~V}$ & $1.99 \mathrm{~V}$ & $\begin{array}{l}45.3 \\
\mathrm{dBA}\end{array}$ & $91.1 \mathrm{dBA}$ & $\begin{array}{c}\text { Putaran potensio pertama, sensor } \\
\text { menerima suara }\end{array}$ \\
\hline $\mathrm{Ke}-2$ & $1.62 \mathrm{~V}$ & $1.59 \mathrm{~V}$ & $\begin{array}{l}44.2 \\
\mathrm{dBA}\end{array}$ & $92.7 \mathrm{dBA}$ & $\begin{array}{c}\text { Putaran potensio kedua, sensor } \\
\text { menerima suara }\end{array}$ \\
\hline $\mathrm{Ke}-3$ & $1.38 \mathrm{~V}$ & $1.35 \mathrm{~V}$ & $\begin{array}{l}46.1 \\
d B A\end{array}$ & $92.8 \mathrm{dBA}$ & $\begin{array}{c}\text { Putaran potensio ketiga, sensor } \\
\text { menerima suara }\end{array}$ \\
\hline $\mathrm{Ke}-4$ & $1.17 \mathrm{~V}$ & $1.15 \mathrm{~V}$ & $\begin{array}{l}48.0 \\
\mathrm{dBA}\end{array}$ & $92.9 \mathrm{dBA}$ & $\begin{array}{c}\text { Putaran potensio keempat, sensor } \\
\text { menerima suara }\end{array}$ \\
\hline $\mathrm{Ke}-5$ & $0.77 \mathrm{~V}$ & $0.75 \mathrm{~V}$ & $\begin{array}{l}42.6 \\
d B A\end{array}$ & $93.6 \mathrm{dBA}$ & $\begin{array}{c}\text { Putaran potensio kelima, sensor } \\
\text { menerima suara }\end{array}$ \\
\hline $\mathrm{Ke}-6$ & $0.64 \mathrm{~V}$ & $0.62 \mathrm{~V}$ & $\begin{array}{l}41.9 \\
\text { dBA }\end{array}$ & $93.8 \mathrm{dBA}$ & $\begin{array}{c}\text { Putaran potensio keenam, sensor } \\
\text { menerima suara }\end{array}$ \\
\hline $\mathrm{Ke}-7$ & $0.48 \mathrm{~V}$ & $0.46 \mathrm{~V}$ & $\begin{array}{l}42.3 \\
d B A\end{array}$ & $93.9 \mathrm{dBA}$ & $\begin{array}{l}\text { Putaran potensio ketujuh, sensor } \\
\text { menerima suara }\end{array}$ \\
\hline $\mathrm{Ke}-8$ & $0.43 \mathrm{~V}$ & $0.42 \mathrm{~V}$ & $\begin{array}{l}42.7 \\
d B A\end{array}$ & $94.4 \mathrm{dBA}$ & $\begin{array}{l}\text { Putaran potensio kedelapan, } \\
\text { sensor menerima suara }\end{array}$ \\
\hline $\mathrm{Ke}-9$ & $0.28 \mathrm{~V}$ & $0.27 \mathrm{~V}$ & $\begin{array}{l}41.6 \\
d B A\end{array}$ & $95.1 \mathrm{dBA}$ & $\begin{array}{l}\text { Putaran potensio kesembilan, } \\
\text { sensor menerima suara }\end{array}$ \\
\hline $\mathrm{Ke}-10$ & $0.25 \mathrm{~V}$ & $0.24 \mathrm{~V}$ & $\begin{array}{l}41.8 \\
\mathrm{dBA}\end{array}$ & $95.4 \mathrm{dBA}$ & $\begin{array}{l}\text { Putaran potensio kesepuluh, } \\
\text { sensor menerima suara }\end{array}$ \\
\hline
\end{tabular}

Pengukuran yang dilakukan dengan memutar potensio pada sensor berlawanan arah jarum jam agar sensor dalam keadaan sangat sensitif terhadap semua suara atau dengan sebutan lain posisi awal potensio. Pengukuran berikutnya dengan memutar potensio searah jarum jam secara perlahan sehingga mendapatkan hasil yang berbedabeda. Pengukuran dilakukan sampai potensio tidak dapat diputar lagi sehingga dapat diketahui nilai maksimum suara yang dapat diterima oleh sensor. Intensitas sensor suara FC-04 dari 91,1 dBA pada putaran awal potensio dan 95,4 dBA pada putaran akhir potensio. Jadi dapat disimpulkan bahwa nilai dari intensitas sensor suara FC04 berkisar 91,1 dBA sampai 95,4 dBA. Jika suara kurang dari 91,1 dBA maka sensor tidak akan mendeteksi suara tersebut dan jika suara lebih dari 95,4 dBA maka sensor tidak dapat mendeteksi suara tersebut. Pengukuran tegangan yang dilakukan pada kaki potensio, maksimal dalam keadaaan tidak menerima suara sebesar $1.99 \mathrm{~V}$ sedangkan jika dalam keadaan menerima suara sebesar $2.03 \mathrm{~V}$. Tegangan minimum dalam keadaan tidak menerima suara sebesar $0.24 \mathrm{~V}$ dan jika menerima suara tegangannya sebesar $0.25 \mathrm{~V}$.

\section{SIMPULAN}

Berdasarkan uraian-uraian sebelumnya dapat disimpulkan:

a. Rancang bangun alat ini sudah bisa diaplikasikan dengan kemampuan mendeteksi suara. Suara yang dapat diterima harus memenuhi kapasitas intensitasnya. Jika tidak, maka sensor tidak akan mendeteksi suara tersebut. Alat sistem pengaman kunci otomatis ini dapat dijadikan sebagai media pembelajaran bagi mahasiswamahasiswa yang mempunyai ide kreatif sehingga dapat membuat alat sistem pengaman yang lebih inovatif.

b. Kemampuan mendeteksi sensor suara FC-04 tergantung pada pengaturan potensimeternya. Untuk tingkat keamanan yang signifikan maka diatur potensiometer untuk suara yang tinggi. Sehingga intensitas suara yang diterima juga harus tinggi. Jika ada orang yang Jurnal Sains dan Teknologi | 124 
ingin melakukan pencurian dan orang tersebut mengetahui tentang cara kerja dari kunci tersebut maka pencuri tersebut akan mengeluarkan suara yang bervolume tinggi. Sehingga mudah untuk mendengar orang yang akan membuka pintu tersebut.

c. Waktu ketika terbukanya kunci dapat diatur pada program sesuai dengan yang diinginkan.

d. Alat ini dapat diimplementasikan pada pintu atau jendela rumah, ruangan kerja, pintu pagar dan masih banyak lagi objek yang bisa dipasang menggunakan kunci otomatis ini.

\section{DAFTAR PUSTAKA}

Ario, G. R. (2015). Magnetic Door Lock Menggunakan kode Pengaman Berbasis Atmega 328. Universitas Negeri Yogyakarta. Yogyakarta.

Badan Pusat Statistik. (2016). Jumlah Tindak Pidana Menurut Kepolisian Daerah, 2000 - 2016. Retrieved February 10, 2018, from https://www.bps.go.id/statictable/2009/ 02/21/1570/jumlah-tindak-pidanamenurut-kepolisian-daerah-2000--2016.html

Lawu, B. L., Adiono, T., Putra, R. V. W., Fathany, M. Y., Afifah, K., Santriaji, M. H., \& Fuada, S. (2016). Prototyping design of electronic end-devices for smart home applications. Proceedings - 2016 IEEE Region 10 Symposium, TENSYMP 2016, 4(c), 261-265. https://doi.org/10.1109/TENCONSpring .2016 .7519415

Raka Agung, I. S. (2012). Rancang Bangun Prototipe Penghitung Jumlah Orang Dalam Ruangan Terpadu Berbasis Mikrokontroler Atmega328P, 11, 132206.

S. Anderson. (2014). The making off controlling system to sliding door for house. Poli Rekayasa, Vol.10 no., 7385.

Saputro, Eko dan Wibawanto, H. (2016). Rancang Bangun Pengaman Pintu Otomatis Menggunakan E-KTP Berbasis Mikrokontroler Atmega328. Jurusan Teknik Elektro, Fakultas Teknik, Universitas Negeri Semarang, Vol 8, No.

Shabani, H., Julai, N., Ahmed, M. M., Helmi, A., \& Rose, C. (n.d.). Intelligent Greenhouse Monitoring and Control System Based Arduino UNO Microcontroller, 9(3), 65-69.

Stankovic, J. A., Lee, I., Mok, A., \& Rajkumar, R. (2005). Opportunities and obligations for physical computing systems. Computer, 38(11), 23-31. https://doi.org/10.1109/MC.2005.386 